Article

\title{
Anthocyanin Structure and pH Dependent Extraction Characteristics from Blueberries (Vaccinium corymbosum) and Chokeberries (Aronia melanocarpa) in Subcritical Water State
}

\author{
Hye-Ji Kang ${ }^{1, \dagger}{ }^{+}$Min-Jung Ko ${ }^{2,+}$ and Myong-Soo Chung $1, * \mathbb{C}$ \\ 1 Department of Food Science and Engineering, Ewha Womans University, Seoul 03760, Korea; \\ kjskai2013@naver.com \\ 2 Department of Food Science and Biotechnology, Global K-Food Research Center, \\ Hankyong National University, Anseong-si 17579, Korea; mjko@hknu.ac.kr \\ * Correspondence: mschung@ewha.ac.kr; Tel.: +82-2-3277-4445 \\ + Co-first author, these authors contributed equally to this work.
}

check for

updates

Citation: Kang, H.-J.; Ko, M.-J.; Chung, M.-S. Anthocyanin Structure and $\mathrm{pH}$ Dependent Extraction

Characteristics from Blueberries

(Vaccinium corymbosum) and

Chokeberries (Aronia melanocarpa) in

Subcritical Water State. Foods 2021, 10

527. https://doi.org/10.3390/

foods10030527

Academic Editor: Zlatina Genisheva

Received: 20 January 2021

Accepted: 28 February 2021

Published: 3 March 2021

Publisher's Note: MDPI stays neutral with regard to jurisdictional claims in published maps and institutional affiliations.

Copyright: (c) 2021 by the authors. Licensee MDPI, Basel, Switzerland. This article is an open access article distributed under the terms and conditions of the Creative Commons Attribution (CC BY) license (https:// creativecommons.org/licenses/by/ $4.0 /)$.

\begin{abstract}
This study determines the optimal extraction conditions for the subcritical-water extraction (SWE) of anthocyanin from blueberries and chokeberries and compares the performance using conventional extraction methods. SWE is carried out under different conditions of extraction temperature $\left(110^{\circ} \mathrm{C}, 130{ }^{\circ} \mathrm{C}, 150{ }^{\circ} \mathrm{C}, 170{ }^{\circ} \mathrm{C}, 190^{\circ} \mathrm{C}\right.$, and $\left.200{ }^{\circ} \mathrm{C}\right)$, extraction time $(1,3,5$, and $10 \mathrm{~min})$, and solvent $\mathrm{pH}$ (water and $1 \%$ citric acid). The solubility and stability of anthocyanin from blueberries and chokeberries influences the optimal condition for SWE. The presence of more methoxy and hydroxyl functional groups in the basic skeleton of anthocyanin will result in a lower solubility at a high temperature. Water at a higher temperature exhibits a better dissociation reaction, and a solvent has a lower $\mathrm{pH}$ at a higher temperature. One percent citric acid is used to reduce the $\mathrm{pH}$ of the solvent, which increases the extraction efficiency of anthocyanin in a subcritical water state.
\end{abstract}

Keywords: blueberries; chokeberries; subcritical-water extraction (SWE); anthocyanin structure

\section{Introduction}

Anthocyanidin is an aglycon form of anthocyanin, which is a colored phenolic compound that exists in nature. The color of anthocyanidin varies with the positions and types of the attached functional groups: as the number of attached functional groups such as hydroxyl and methoxy groups increases, the color of anthocyanidin changes from orange to purple. Anthocyanin pigments are known to exert various health effects, such as high antioxidant activity, reduction of low-density lipoprotein cholesterol, and lowering of arterial stiffness [1-4].

Anthocyanins in plants are mainly distributed in the vacuoles that are present inside cell walls, and are abundant in fruits, vegetables, and flowers [5]. Among fruits, blueberries (Vaccinium corymbosum) content is dominated by $41.4 \%$ malvidin glycoside, then $21.7 \%$ delphinidin glycoside, $19.23 \%$ petunidin glycoside, $12.4 \%$ peonidin glycoside, and $5.2 \%$ cyanidin glycoside. Chokeberries (Aronia melanocarpa) contain the highest amount of anthocyanins, overwhelmingly dominated by cyanidin glycoside $(98.4 \%)$, then $0.08 \%$ petunidin glycoside, $0.3 \%$ malvidin glycoside, $0.3 \%$ pelargonidin glycoside, and $0.2 \%$ delphinidin glycoside [6]. Anthocyanin is sensitive to temperature, light, $\mathrm{pH}$, oxygen, metal ions, and enzymes [7]. Occurring at high temperatures, the C-ring structure is destroyed after removing sugar from anthocyanin [8]. The structure of the anthocyanin also changes with the proton concentration, resulting in anthocyanin being reddish at $\mathrm{pH} 1$, blue at $\mathrm{pH} 2-4$, and colorless at $\mathrm{pH} 5$ or higher [9].

The use of water as a solvent below $100{ }^{\circ} \mathrm{C}$ at atmospheric pressure makes it easy to extract polar compounds due to its high dielectric constant $(\varepsilon)(\varepsilon<80)$, but this is not 
effective for extracting nonpolar phenolic compounds or flavonoids. Subcritical-water extraction (SWE) can overcome these drawbacks, since the dielectric constant of water can be reduced (e.g., from $\varepsilon=53$ at $110^{\circ} \mathrm{C}$ to $\varepsilon=34.5$ at $200{ }^{\circ} \mathrm{C}$ ) below the critical point by applying appropriate pressure and temperature $\left(100-374{ }^{\circ} \mathrm{C}\right)$. The use of converted subcritical water makes it easy to extract less polar compounds and is also environmentally friendly because no organic solvent is used. Previous studies have extracted components such as phenolic compounds and flavonoids using the SWE method [10,11]. Since SWE involves only using water and is cost-effective, rapid, and efficient, it has been applied to extract anthocyanins from plants and fruits, such as the anthocyanins from grape skins and from freeze-dried Sunbelt red grape pomace $[12,13]$. However, SWE has not previously been applied to characteristics of anthocyanin structures and is $\mathrm{pH}$ dependent during the subcritical state of blueberries, and chokeberries.

This study applies the SWE method to extract anthocyanin from blueberries and chokeberries, with the aim of determining the optimum condition such as the time, temperature, and $\mathrm{pH}$ of the solvent for maximizing its extraction efficiency, and their dependence on the chemical structure of anthocyanins. Furthermore, the anthocyanin concentration in the optimum condition is compared with that for conventional extraction methods. The flavonoid content and antioxidant activity of the extracts are evaluated. The $\mathrm{pH}$ differential method and high-performance liquid chromatography (HPLC) are performed to analyze the blueberry and chokeberry extracts, and the correlation between the findings of these two methods also is analyzed.

\section{Materials and Methods}

\subsection{Materials}

Frozen blueberries ( $14 \mathrm{~mm}$, about $3 \mathrm{~g}$ ), and chokeberries (14 mm, about $2.8 \mathrm{~g}$ ) were obtained from Pyeongtaek and Gochang in Korea. These berries were harvested in 2019. Samples were dried for $24 \mathrm{~h}$ using a freeze dryer (FD8523, Ilshin, Gyeonggi-do, Korea). The obtained samples dried to a moisture content of $<20 \%$ were passed through a 20-mesh sieve and stored in the dark at $-4{ }^{\circ} \mathrm{C}$ prior to performing the extraction process.

Anthocyanins are commonly unstable to processing and storage. Previous studies regarding anthocyanin stability in frozen storage up to 4 months found it did not significantly affect the anthocyanins of berries [14] and grinding for extraction had positive effects on the anthocyanin yield due to the increase in surface area [15]. However, a high temperature for sample drying negatively influenced anthocyanin stability $[14,16]$. Therefore, samples of blueberries and chokeberries were dried using a freeze dryer in this study.

\subsection{Chemicals and Reagents}

Standard malvidin-3-galactoside chloride (molecular weight $=528.89$, purity grade $\geq 95 \%$ ), and cyanidin-3-galactoside chloride (molecular weight $=484.84$, purity grade $\geq 95 \%$ ) were purchased from Sigma-Aldrich (Yongin, Gyunggi-do, Korea) and Dongmyung Scientific (Seoul, Korea). $\mathrm{CH}_{2} \mathrm{O}_{2}$ (formic acid), $\mathrm{C}_{2} \mathrm{H}_{4} \mathrm{O}_{2}$ (glacial acetic acid), $\mathrm{CH}_{3} \mathrm{CN}$ (acetonitrile), and $\mathrm{H}_{3} \mathrm{PO}_{4}$ (phosphoric acid) of an analytical grade were purchased from Duksan (Ansan, Gyeonggi-do, Korea). Water and $\mathrm{CH}_{3} \mathrm{OH}$ (methanol; high-performance liquid chromatography (HPLC) grade) were obtained from J.T. Baker (Phillipsburg, NJ, USA). The buffer was made using $\mathrm{HCl}$ (hydrogen chloride), $\mathrm{KCl}$ (potassium chloride), and $\mathrm{C}_{2} \mathrm{H}_{3} \mathrm{NaO}_{2}$ (sodium acetate) obtained from Duksan.

\subsection{Extraction Methods}

The subcritical-water extraction (SWE) process was performed using an accelerated solvent extractor (ASE 350, Dionex, Sunnyvale, CA, USA) with Milli-Q water (MR-RO800, Mirae ST, Anyang, Korea). The dried sample (1 g) and diatomaceous earth (2 g, Dionex) were placed in a stainless-steel extraction cell $(23 \mathrm{~mm}$ i.d. $\times 50 \mathrm{~mm}$ long, $22 \mathrm{~mL}$; Dionex) containing a cellulose filter. Extraction was performed under various temperatures $\left(110-200{ }^{\circ} \mathrm{C}\right)$ and times (1-10 min). Subcritical solvent extraction also was performed using $1 \%$ citric 
acid as the subcritical solvent under the SWE optimum conditions $\left(130^{\circ} \mathrm{C}\right.$ for $3 \mathrm{~min}$ for blueberries, $190^{\circ} \mathrm{C}$ for $1 \mathrm{~min}$ for chokeberries).

The accelerated solvent extractor was set up in the bypass heat-up mode, and a rinse process was carried out between successive extractions. The extraction process was as follows: The sample cell was loaded into the oven once it had reached the pre-set temperature. The pump was then operated to fill the cell with solvent and, once the cell contents had reached the set temperature, it was maintained for the set extraction time under constant pressure (about 100 bar). Once the extraction time had elapsed, the extract from the cell was transferred to the collection bottle along the line through the filter using nitrogen gas.

To confirm the anthocyanin extraction efficiency of the SWE method, conventional extraction methods were applied by pressing blueberry and chokeberry juice and applying a hot-water extraction method. The pressed-juice extract was prepared by thawing frozen blueberries and chokeberries at room temperature $\left(25^{\circ} \mathrm{C}\right)$, applying pressure, and then extracting the juice after screening. Hot-water extraction was performed by mixing $1 \mathrm{~g}$ of a powder sample and $22 \mathrm{~mL}$ of distilled water (DW) in a water bath maintained at $60^{\circ} \mathrm{C}$ for $1 \mathrm{~h}$. The extraction processes were performed in the dark, and all experiments were conducted in triplicate.

The extracted blueberry and chokeberry extracts were kept in a deep freezer at $-80{ }^{\circ} \mathrm{C}$ for more than $12 \mathrm{~h}$ and then dried for $24 \mathrm{~h}$ using a freeze dryer. The dried extract was dissolved in $15 \mathrm{~mL}$ of methanol and vortexed, and then centrifugation was performed at $4000 \mathrm{rpm}$ for $20 \mathrm{~min}$ to separate the solid and supernatant. The supernatant was passed through a $0.45-\mu \mathrm{m} 13-\mathrm{mm}$-long polyvinylidene fluoride (PVDF) filter (Syringe Filter, Whatman, NJ, USA) before being analyzed.

\subsection{Determination of Total Anthocyanin Contents}

The anthocyanin content was determined using the $\mathrm{pH}$ differential method. The color of anthocyanin varies with the $\mathrm{pH}$, being reddish at $\mathrm{pH} 1$ and colorless at $\mathrm{pH} 4.5$, so samples were diluted in buffers at $\mathrm{pH} 1$ (prepared using $\mathrm{HCl}$ and sodium acetate) and $\mathrm{pH} 4.5$ (prepared using $\mathrm{HCl}$ and $\mathrm{KCl}$ ). A 0.1-mL aliquot of each sample was added to $1.4 \mathrm{~mL}$ of each buffer and vortexed. The absorbance was then measured at 510 and $700 \mathrm{~nm}$ with a spectrophotometer to predict the anthocyanin content using the following formula:

$$
\text { Anthocyanin }(\mathrm{mg} / \mathrm{L})=\frac{\mathrm{A} \times 1000 \times \mathrm{MW} \times \mathrm{DF}}{\varepsilon \times 1}
$$

where $\mathrm{A}=\left(\mathrm{A}_{510 \mathrm{~nm}}-\mathrm{A}_{700 \mathrm{~nm}}\right.$ at $\left.\mathrm{pH} 1\right)-\left(\mathrm{A}_{510 \mathrm{~nm}}-\mathrm{A}_{700 \mathrm{~nm}}\right.$ at $\left.\mathrm{pH} 4.5\right), \mathrm{MW}=$ molecular weight of standard anthocyanin, $\mathrm{DF}=$ dilution factor, $1=$ path length $($ in $\mathrm{cm}), \varepsilon=$ molar extinction coefficient (in $\mathrm{L} / \mathrm{mol} / \mathrm{cm}$ ), and $1000=$ factor for converting from grams to milligrams [17].

\subsection{High-Performance Liquid Chromatography (HPLC) and Mass Spectrometry (MS)}

The extracts were simply pretreated and quantitatively analyzed by high-performance liquid chromatography (HPLC) (1260 Infinity, Agilent Technologies, Waldbronn, Germany) with a Zorbax C18 column $(4.6 \mathrm{~mm} \times 100 \mathrm{~mm}, 5 \mu \mathrm{m}$ pore size; Agilent Technologies, Waldbronn, Germany). The HPLC analysis method followed a modified version of the method reported by Kalt et al. [18] for analyzing blueberry extracts. The mobile phase used for analysis comprised $5 \%$ aqueous formic acid (solvent A) and methanol (solvent B). The percentage of solvent B was increased from $14 \%$ to $17 \%$ over $10 \mathrm{~min}$, then to $23 \%$ over $25 \mathrm{~min}$, then to $47 \%$ over $30 \mathrm{~min}$, then to $14 \%$ over $2 \mathrm{~min}$, and then to $14 \%$ over $3 \mathrm{~min}$. The injection volume was $50 \mu \mathrm{L}$ and the flow rate was $1 \mathrm{~mL} / \mathrm{min}$. Detection was performed at $515 \mathrm{~nm}$ using a Ultraviolet (UV) detector (Agilent Technologies, Waldbronn, Germany). The HPLC analysis method followed a modified version of the method reported by Chandra et al. [19] for analyzing chokeberry extracts. The mobile phase used for analysis comprised $0.5 \%$ aqueous phosphoric acid (solvent $\mathrm{A}$ ) and water:acetonitrile:glacial acetic 
acid:phosphoric acid at 50:48.5:1.0:0.5 $(v / v / v / v)$ (solvent B). The percentage of solvent B was increased from 0 to $20 \%$ over $26 \mathrm{~min}$, then to $60 \%$ over $4 \mathrm{~min}$, and then to $20 \%$ over $5 \mathrm{~min}$. The injection volume was $10 \mu \mathrm{L}$ and the flow rate was $0.8 \mathrm{~mL} / \mathrm{min}$. Detection was performed at $520 \mathrm{~nm}$ using a UV detector.

HPLC mass spectrometry (MS) was performed using a quadrupole time-of-flight mass spectrometer (6530 Accurate-Mass Q-TOF, Agilent Technologies, Waldbronn, Germany) equipped with an electrospray ionization source. The analysis parameters were set using positive-ion modes. The mobile phase used for the analysis of the chokeberry extracts comprised $0.1 \%$ formic acid in water (solvent $\mathrm{A}$ ) and $0.1 \%$ formic acid in acetonitrile (solvent B). The injection volume was $5 \mu \mathrm{L}$ and flow rate was $0.4 \mathrm{~mL} / \mathrm{min}$, with an initial solvent A:solvent B ratio of 90:10. The ratio of solvent B was changed as follows: to $12 \%$ over $8 \mathrm{~min}$, to $15 \%$ over $10 \mathrm{~min}$, to $15 \%$ over $15 \mathrm{~min}$, to $55 \%$ over $18 \mathrm{~min}$, to $90 \%$ over $20 \mathrm{~min}$, and to $5 \%$ over $22 \mathrm{~min}$.

The extracts were quantitatively identified by HPLC, and more accurately qualitatively analyzed by HPLC mass spectrometry.

\subsection{Total Flavonoid Content}

The $\mathrm{AlCl}_{3}$ (aluminum chloride) colorimetric method was used to determine the total flavonoid content. The sample $(1 \mathrm{~mL})$ was mixed with $0.3 \mathrm{~mL}$ of $\mathrm{NaNO}_{2}$ (sodium nitrite; $5 \%, w / v)$ and reacted for $5 \mathrm{~min}$. Subsequently, $0.5 \mathrm{~mL}$ of $\mathrm{AlCl}_{3}(2 \%, w / v)$ was added and reacted for $6 \mathrm{~min}$. Finally, $0.5 \mathrm{~mL}$ of $1 \mathrm{M} \mathrm{NaOH}$ (sodium hydroxide) was added and reacted for $10 \mathrm{~min}$ and the absorbance was then measured at $510 \mathrm{~nm}$. Catechin was used to obtain a standard curve and the total flavonoid contents were expressed in milligrams of catechin equivalent (CE) per gram fresh weight (FW).

\subsection{Antioxidant Activity}

The ferric-reducing antioxidant power (FRAP) assay was used to measure the antioxidant activity of the extracts. The reagents were prepared for the FRAP assay as follows: To prepare the $300 \mathrm{mM}$ acetate buffer, $3.1 \mathrm{~g}$ of $\mathrm{C}_{2} \mathrm{H}_{3} \mathrm{NaO}_{2} \cdot 3 \mathrm{H}_{2} \mathrm{O}$ (sodium acetate trihydrate) was added to $16 \mathrm{~mL}$ of $\mathrm{C}_{2} \mathrm{H}_{4} \mathrm{O}_{2}$ (glacial acetic acid), with distilled water (DW) added to bring the total volume to $1 \mathrm{~L}$. The 2,4,6-tri(2-pyridyl)-s-triazine (TPTZ) solution (10 mM) was prepared by adding $3.1233 \mathrm{~g}$ of TPTZ to $1 \mathrm{~L}$ of $40 \mathrm{mM} \mathrm{HCl}$, and the $\mathrm{FeCl}_{3} \cdot 6 \mathrm{H}_{2} \mathrm{O}$ solution was prepared by adding $1 \mathrm{~L}$ of DW to $5.406 \mathrm{~g}$ of $\mathrm{FeCl}_{3} \cdot 6 \mathrm{H}_{2} \mathrm{O}$. The working FRAP reagent was made by mixing the $300 \mathrm{mM}$ acetate buffer, $10 \mathrm{mM} \mathrm{TPTZ}$, and $\mathrm{FeCl}_{3} \cdot 6 \mathrm{H}_{2} \mathrm{O}$ solution at a ratio of $10: 1: 1$, and then preheated at $37^{\circ} \mathrm{C}$. The sample $(10 \mu \mathrm{L})$ and $300 \mu \mathrm{L}$ of working FRAP reagent were reacted on a 96-well plate and incubated for $5 \mathrm{~min}$ at $37^{\circ} \mathrm{C}$ in the dark. The absorbance was measured at $593 \mathrm{~nm}$. Trolox was used to obtain a standard curve, and the antioxidant activity was expressed in milligrams of trolox equivalent (TE) per gram fresh weight (FW).

\subsection{Scanning Electron Microscopy}

Images of the chokeberry powder were obtained using an environmental scanning electron microscopy (SEM; FEI XL-30FEG, FEI, Burlington, VT, USA) at the Korea Institute of Science and Technology.

\subsection{Data Analysis}

Pearson's correlation coefficients were calculated as were Tukey's test, and a one-way analysis of variance with Duncan's test applied using SPSS Statistics software (version 22, IBM SPSS, IL, USA) with a probability cutoff for statistical significance of $p<0.05$.

\section{Results and Discussion}

\subsection{Results from $p H$ Differential Method and High-Performance Liquid Chromatography (HPLC) Analysis}

The malvidin-3-galactoside and cyanidin-3-galactoside standards for high-performance liquid chromatography (HPLC) analysis were diluted in methanol at concentrations of 
$0.03125,0.0625,0.125,0.25,0.5$, and $1 \mathrm{mg} / \mathrm{mL}$. The standard curves $\mathrm{y}=35650 \mathrm{x}-270.83$ $\left(\mathrm{R}^{2}=0.99\right)$ for malvidin-3-galactoside, and $\mathrm{y}=28550 \mathrm{x}-774.86\left(\mathrm{R}^{2}=0.99\right)$ for cyanidin3-galactoside were obtained. All the extracts obtained from blueberries and chokeberries were analyzed by HPLC; their HPLC chromatograms are shown in Figure S1.

A preliminary experiment was conducted to set the measurement wavelength to reduce the measurement error of the $\mathrm{pH}$ differential method. Extraction samples were loaded into the $\mathrm{pH} 1$ and $\mathrm{pH} 4.5$ buffers and the absorbance was measured across all wavelengths. This revealed that the absorbance difference between the two buffers was largest at $510 \mathrm{~nm}$, with no difference observed at $700 \mathrm{~nm}$ (Figure S2). Therefore, the measured wavelengths were set as 510 and $700 \mathrm{~nm}$.

The $\mathrm{pH}$ differential method is an analytical method based on the color of anthocyanin varying with $\mathrm{pH}$, whereas the HPLC method predicts the content in a sample using a standard [17]. This study analyzed the blueberry and chokeberry extracts using both the $\mathrm{pH}$ differential method and the HPLC method, and the correlation between the $\mathrm{pH}$ differential method and the HPLC method also was analyzed (Figure S3). The correlation coefficient for the blueberry and chokeberry samples were 0.967 , and 0.986, respectively. Although the strong correlation indicated that the two analytical methods showed similar tendencies, the content was lower when using the $\mathrm{pH}$ differential method than when using the HPLC method. The pH differential method is known to be less accurate than the HPLC method, but the cost of the anthocyanin standard is very high due to the difficulty in purifying it. This situation prompted the development of the $\mathrm{pH}$ differential method, which can be used to easily estimate the anthocyanin content using a spectrophotometer in a laboratory without requiring an anthocyanin standard.

The following factors contributed to the different results obtained when using the two methods: the moisture content, the hygroscopicity of the anthocyanins, the presence of impurities (polyphenolics or polymeric anthocyanins), the molar extinction coefficient, and the measured absorbance values. These factors resulted in the content measured using the $\mathrm{pH}$ differential method generally being lower than that for HPLC. A previous study by Lee et al. [17] also found a difference in the anthocyanin content between the $\mathrm{pH}$ differential method (3.56 mg/100 mL) and HPLC analysis (14.09 mg/100 mL).

\subsection{Optimal Conditions of Subcritical-Water Extraction (SWE) from Blueberry and Chokeberry}

The contents of anthocyanin in blueberries obtained using subcritical-water extraction (SWE) at $110{ }^{\circ} \mathrm{C}, 130^{\circ} \mathrm{C}, 150{ }^{\circ} \mathrm{C}$, and $170{ }^{\circ} \mathrm{C}$ for $1,3,5$, and $10 \mathrm{~min}$ are shown in Figure 1. The optimal condition for the SWE of blueberries was $130{ }^{\circ} \mathrm{C}$ for $3 \mathrm{~min}$, which produced an anthocyanin content of $0.47 \pm 0.03 \mathrm{mg} / \mathrm{g}$ of fresh weight (FW) (mean \pm SD) and a malvidin-3-galactoside content of $0.18 \pm 0.02 \mathrm{mg} / \mathrm{g}$ of FW. Seen at $110{ }^{\circ} \mathrm{C}$ and $130{ }^{\circ} \mathrm{C}$, the content of anthocyanin increased and then decreased with an increasing extraction time over $3 \mathrm{~min}$. Conversely, the anthocyanin content decreased exponentially with an increasing extraction time at $150{ }^{\circ} \mathrm{C}$ and $170{ }^{\circ} \mathrm{C}$ temperatures.

The anthocyanin components of blueberry SWE extracts were identified by highperformance liquid chromatography-mass spectrometry (HPLC-MS) analysis (Table 1). Thirteen anthocyanins were detected: cyanidin-3-arabinoside, cyanidin-3-galactoside, cyanidin-3-glucoside, delphinidin-3-galactoside, delphinidin-3-glucoside, peonidin-3galactoside, delphindin-3-arabinoside, petunidin-3-arabinoside, malvidin-3-galactoside, petunidin-3-galactoside, petunidin-3-glucoside, malvidin-3-glucoside, and malvidin-3-arabinoside. 

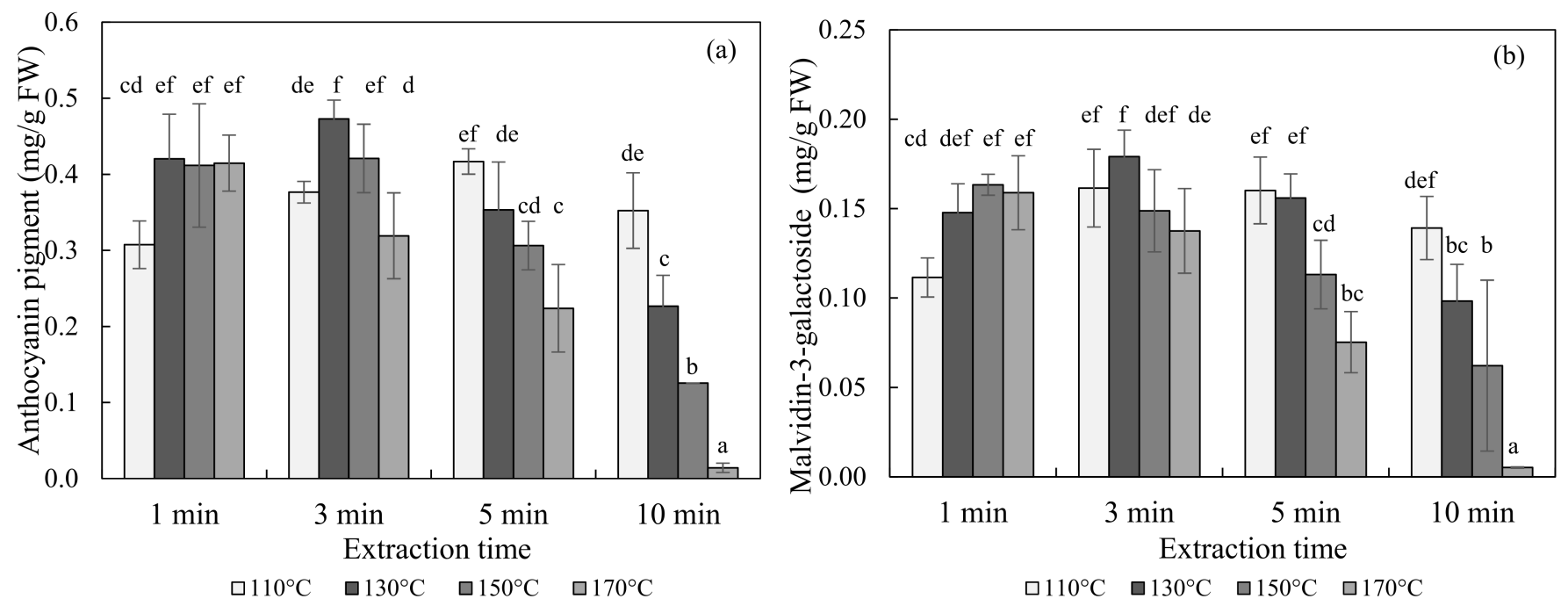

Figure 1. Anthocyanin pigment (a) and malvidin-3-galactoside (b) concentrations of blueberry extracts obtained using subcritical-water extraction (SWE) as analyzed by the $\mathrm{pH}$ differential method and high-performance liquid chromatography (HPLC) analysis. Means in bars with same letters are not significantly different according to Duncan's test at $p<0.05$. Data are mean and SD values $(n=3)$. FW (fresh weight)

Table 1. Identification of anthocyanins detected by high-performance liquid chromatography-mass spectrometry in blueberry, and chokeberry extracts.

\begin{tabular}{|c|c|c|c|c|c|c|c|c|}
\hline Fruits & Peak & $\begin{array}{l}\text { Retention } \\
\text { Time (min) }\end{array}$ & {$[M]+(m / z)$} & Anthocyanin & Chemical Structure & $\mathbf{R}^{1}$ & $\mathbf{R}^{2}$ & $\mathrm{OR}^{3}$ \\
\hline \multirow{11}{*}{ Blueberry } & 1 & 9.931 & 419.1817 & $\begin{array}{l}\text { cyanidin-3- } \\
\text { arabinoside }\end{array}$ & & $\mathrm{H}$ & $\mathrm{OH}$ & arabinose \\
\hline & 2 & 10.022 & 449.1723 & $\begin{array}{l}\text { cyanidin-3- } \\
\text { galactoside }\end{array}$ & & $\mathrm{H}$ & $\mathrm{OH}$ & galactose \\
\hline & 3 & 10.333 & 449.177 & $\begin{array}{l}\text { cyanidin-3- } \\
\text { glucoside }\end{array}$ & & $\mathrm{H}$ & $\mathrm{OH}$ & glucose \\
\hline & 4 & 10.881 & 465.1002 & $\begin{array}{l}\text { delphinidin-3- } \\
\text { galactoside }\end{array}$ & & $\mathrm{OH}$ & $\mathrm{OH}$ & galactose \\
\hline & 5 & 11.287 & 465.1007 & $\begin{array}{l}\text { delphinidin-3- } \\
\text { glucoside }\end{array}$ & & $\mathrm{OH}$ & $\mathrm{OH}$ & glucose \\
\hline & 6 & 11.903 & 463.2499 & $\begin{array}{l}\text { peonidin-3- } \\
\text { galactoside }\end{array}$ & & $\mathrm{H}$ & $\mathrm{OMe}$ & galactose \\
\hline & 7 & 12.191 & 435.0865 & $\begin{array}{l}\text { delphindin-3- } \\
\text { arabinoside }\end{array}$ & & $\mathrm{OH}$ & $\mathrm{OH}$ & arabinose \\
\hline & 8 & 13.556 & 449.1049 & $\begin{array}{l}\text { petunidin-3- } \\
\text { arabinoside }\end{array}$ & & $\mathrm{OH}$ & $\mathrm{OMe}$ & arabinose \\
\hline & 9 & 15.126 & 493.0985 & $\begin{array}{l}\text { malvidin-3- } \\
\text { galactoside }\end{array}$ & & $\mathrm{OMe}$ & $\mathrm{OMe}$ & galactose \\
\hline & 10 & 16.766 & 479.1156 & $\begin{array}{l}\text { petunidin-3- } \\
\text { galactoside }\end{array}$ & & $\mathrm{OH}$ & $\mathrm{OMe}$ & galactose \\
\hline & 11 & 16.877 & 479.1251 & $\begin{array}{l}\text { petunidin-3- } \\
\text { glucoside }\end{array}$ & & $\mathrm{OH}$ & $\mathrm{OMe}$ & glucose \\
\hline \multirow{10}{*}{ Chokeberry } & 12 & 17.101 & 493.1353 & $\begin{array}{l}\text { malvidin-3- } \\
\text { glucoside }\end{array}$ & & $\mathrm{OMe}$ & $\mathrm{OMe}$ & glucose \\
\hline & 13 & 20.697 & 463.2991 & $\begin{array}{l}\text { malvidin-3- } \\
\text { arabinoside }\end{array}$ & & $\mathrm{OMe}$ & $\mathrm{OMe}$ & arabinose \\
\hline & 1 & 0.918 & 287.110 & cyanidin & & $\mathrm{H}$ & $\mathrm{OH}$ & \\
\hline & 2 & 9.928 & 419.160 & $\begin{array}{l}\text { cyanidin-3- } \\
\text { arabinoside }\end{array}$ & & $\mathrm{H}$ & $\mathrm{OH}$ & arabinose \\
\hline & 3 & 10.016 & 449.152 & $\begin{array}{l}\text { cyanidin-3- } \\
\text { galactoside }\end{array}$ & & $\mathrm{H}$ & $\mathrm{OH}$ & galactose \\
\hline & 4 & 10.338 & 449.156 & $\begin{array}{l}\text { cyanidin-3- } \\
\text { glucoside }\end{array}$ & & $\mathrm{H}$ & $\mathrm{OH}$ & glucose \\
\hline & 5 & 10.874 & 465.081 & $\begin{array}{l}\text { delphinidin-3- } \\
\text { galactoside }\end{array}$ & & $\mathrm{OH}$ & $\mathrm{OH}$ & galactose \\
\hline & 6 & 11.281 & 465.080 & $\begin{array}{l}\text { delphinidin-3- } \\
\text { glucoside }\end{array}$ & & $\mathrm{OH}$ & $\mathrm{OH}$ & glucose \\
\hline & 7 & 12.182 & 435.079 & $\begin{array}{l}\text { delphindin-3- } \\
\text { arabinoside }\end{array}$ & & $\mathrm{OH}$ & $\mathrm{OH}$ & arabinose \\
\hline & 8 & 20.696 & 463.28 & $\begin{array}{l}\text { malvidin-3- } \\
\text { arabinoside }\end{array}$ & & $\mathrm{OMe}$ & $\mathrm{OMe}$ & arabinose \\
\hline
\end{tabular}


Table 2 indicates that the concentration of anthocyanin at the optimal SWE condition was about 4.5 times higher than that of pressed juice $(0.04 \pm 0.00 \mathrm{mg} / \mathrm{g} \mathrm{FW})$ and about 1.5 times higher than that for the extract obtained using hot water $(0.12 \pm 0.01 \mathrm{mg} / \mathrm{g} \mathrm{FW})$. The subcritical water at $100{ }^{\circ} \mathrm{C}$ or higher had a lower dielectric constant than that of water at $60^{\circ} \mathrm{C}$, thus affecting the extraction efficiency of anthocyanin.

Table 2. Comparison of the efficiency of extracting anthocyanin from blueberries and chokeberries according to the extraction conditions $(n=3)$. Fresh weight $(F W)$. Means in a row followed by same superscript letters are not significantly different according to Duncan's test at $p<0.05$. Data are mean and SD values.

\begin{tabular}{ccccc}
\hline \multirow{2}{*}{ Fruits } & Anthocyanin & \multicolumn{3}{c}{ Extraction Method (mg/g FW) } \\
\cline { 2 - 4 } Blueberry & $\begin{array}{c}\text { Anthocyanin } \\
\text { pigment } \\
\text { Malvidin-3- } \\
\text { galactoside }\end{array}$ & $0.47 \pm 0.03^{\mathrm{a}}$ & $0.12 \pm 0.02^{\mathrm{c}}$ & $0.37 \pm 0.05^{\mathrm{b}}$ \\
& Subcritical Water & Pressed Juice & Hot Water \\
\hline \multirow{2}{*}{ Chokeberry } & $\begin{array}{c}\text { Anthocyanin } \\
\text { pigment } \\
\text { Cyanidin-3- } \\
\text { galactoside }\end{array}$ & $0.66 \pm 0.02^{\mathrm{a}}$ & $0.04 \pm 0.00^{\mathrm{c}}$ & $0.12^{\mathrm{a}} \pm 0.01^{\mathrm{b}}$ \\
\hline
\end{tabular}

The content of anthocyanin in chokeberries obtained using SWE at $110{ }^{\circ} \mathrm{C}, 130^{\circ} \mathrm{C}$, $150{ }^{\circ} \mathrm{C}, 170{ }^{\circ} \mathrm{C}, 190{ }^{\circ} \mathrm{C}$, and $200^{\circ} \mathrm{C}$ for $1,3,5$, and $10 \mathrm{~min}$ are shown in Figure 2. The optimal condition for the SWE of chokeberries was $190^{\circ} \mathrm{C}$ for $1 \mathrm{~min}$, which produced an anthocyanin content of $0.66 \pm 0.04 \mathrm{mg} / \mathrm{g} \mathrm{FW}$ (mean $\pm \mathrm{SD}$ ) and a cyanidin-3-galactoside content of $1.34 \pm 0.07 \mathrm{mg} / \mathrm{g}$ FW. Occurring at $110{ }^{\circ} \mathrm{C}$ and $130{ }^{\circ} \mathrm{C}$, the content of anthocyanin increased and then decreased with an increasing extraction time. Conversely, the anthocyanin content decreased exponentially with an increasing extraction time at $150{ }^{\circ} \mathrm{C}$, $170{ }^{\circ} \mathrm{C}$, and $190^{\circ} \mathrm{C}$ temperatures.
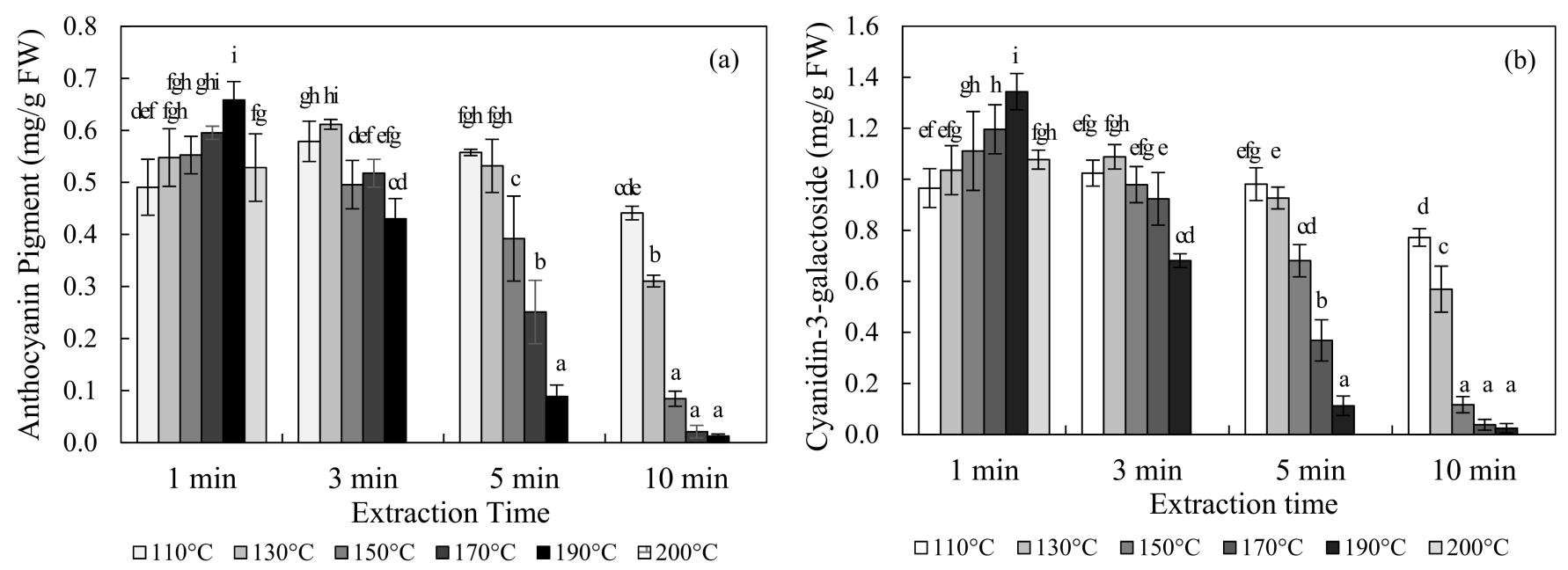

Figure 2. Anthocyanin pigment (a) and cyanidin-3-galactoside (b) concentrations of chokeberry extracts obtained using subcritical-water extraction (SWE) as analyzed by the $\mathrm{pH}$ differential method and high-performance liquid chromatography (HPLC) analysis. Means in bars with same letters are not significantly different according to Duncan's test at $p<0.05$. Data are mean and SD values $(n=3)$. FW (fresh weight).

The anthocyanin components of chokeberry SWE extracts were identified by highperformance liquid chromatography-mass spectrometry (HPLC-MS) analysis. Anthocyanins based on cyanidin and malvidin were the main ones analyzed in the choke- 
berry extracts (Table 1). Eight anthocyanins were detected: aglycone cyanidin, cyanidin3-arabinoside, cyanidin-3-galactoside, cyanidin-3-glucoside, delphinidin-3-galactoside, delphinidin-3-glucoside, delphindin-3-arabinoside, and malvidin-3-arabinoside.

Table 2 indicates that the concentration of anthocyanin at the optimal SWE condition was about 9.5 times higher than that of pressed juice $(0.14 \pm 0.00 \mathrm{mg} / \mathrm{g} \mathrm{FW})$ and about 1.7 times higher than that for the extract obtained using hot water $(0.77 \pm 0.09 \mathrm{mg} / \mathrm{g} \mathrm{FW})$. These findings confirm that the SWE method has the advantages of high extraction efficiency and rapid extraction compared to the conventional extraction methods.

\subsection{Factors Affecting the Optimum Subcritical-Water Extraction (SWE) Condition for Anthocyanins}

Anthocyanin yield following extraction is highly affected by various extraction conditions such as temperature and time. The optimal conditions for the extraction of blueberry (malvidin-3-galactoside, $130{ }^{\circ} \mathrm{C}-3 \mathrm{~min}$ ) and chokeberry (cyanidin-3-galactoside, $190{ }^{\circ} \mathrm{C}-1 \mathrm{~min}$ ) were different. The anthocyanin of the blueberries and chokeberries influenced the optimal condition for subcritical-water extraction (SWE), for which there are several possible reasons. The first is that the solubility of anthocyanins depend on their structure (Table 1). The presence of more methoxy and hydroxyl functional groups in the basic skeleton of anthocyanin will result in a lower solubility. Cyanidin-3-galactoside has four hydroxyl groups in the basic skeleton ring, making it need a higher optimum temperature than malvidin-3-galactoside, which has five methoxy and hydroxyl groups [20,21]. As the temperature increased, the polarity of the water decreased. Occurring at a higher temperature, nonpolar compounds would be dissolved and extracted in a subcritical water state. Regarding the stability of anthocyanins when using the SWE, the results showed that a longer optimum extraction time (malvidin-3-galactoside, $3 \mathrm{~min}$ ) was more stable than cyanidin-3-galactoside (1 $\mathrm{min}$ ) at high temperatures.

The contact area between the solvent and the blueberry and chokeberry samples also could be an influencing factor. The blueberries and chokeberries were dried and pulverized before being used in SWE and scanning electron microscopy (SEM) images of the blueberry and chokeberry powders used for extraction were obtained (Figure 3). The particle size in the extraction of the powders affects extraction efficiency, with the interaction of a chokeberry sample with the solvent being lower when the particles are larger. The optimal extraction temperature of the chokeberries was high to increase the interaction between the solvent and chokeberry powder. Since water at higher temperatures has more energy and a higher diffusion rate, it increases interactions between the solute and solvent. Powders with small particles also have been reported to facilitate diffusion into the plant matrix and provide a greater surface area to provide larger solute and solvent contact [22]. Additionally, the optimal extraction time of chokeberries was relatively short because anthocyanin is sensitive to heat and so degrades when it is exposed to high temperatures for a long time.

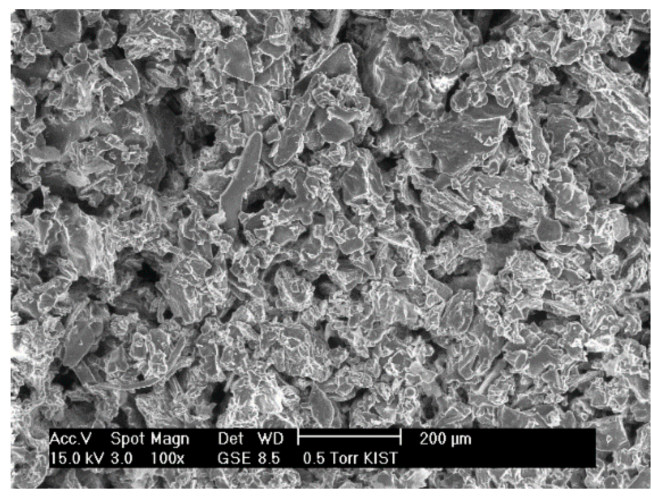

(a)

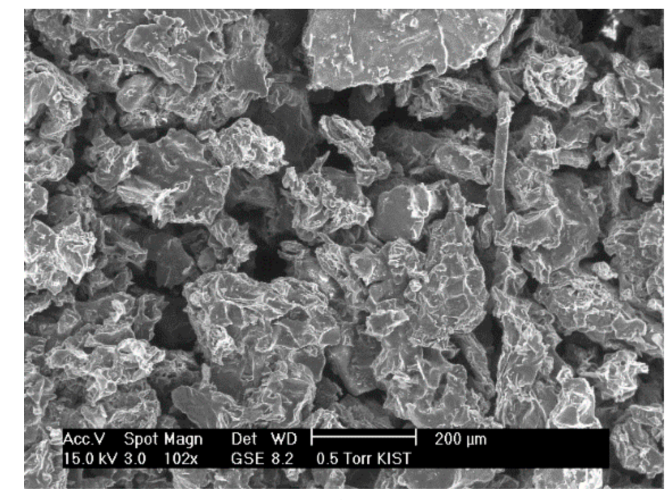

(b)

Figure 3. Scanning electron microscopy (SEM) images of blueberry (a), and chokeberry (b) powder. 


\subsection{Effect of Extraction $\mathrm{pH}$}

Anthocyanins are stable in acid, so extraction also was performed using $1 \%$ citric acid as the solvent under the optimal condition $\left(130^{\circ} \mathrm{C}\right.$ for $3 \mathrm{~min}$ for blueberries, $190^{\circ} \mathrm{C}$ for $1 \mathrm{~min}$ for chokeberries). The anthocyanin content $(0.50 \pm 0.04 \mathrm{mg} / \mathrm{g}$ fresh weight (FW)) and malvidin-3-glactoside content $(0.20 \pm 0.01 \mathrm{mg} / \mathrm{g}$ FW) obtained using $1 \%$ citric acid as the solvent were both higher than the content obtained using subcritical-water extraction (SWE) $(0.47 \pm 0.03 \mathrm{mg} / \mathrm{g}$ FW and $0.18 \pm 0.02 \mathrm{mg} / \mathrm{g}$ FW, respectively) from blueberries. The anthocyanin content $(2.52 \pm 0.47 \mathrm{mg} / \mathrm{g} \mathrm{FW})$ and cyanidin-3-glactoside content ( $3.77 \pm 0.08 \mathrm{mg} / \mathrm{g} \mathrm{FW}$ ) obtained using $1 \%$ citric acid as the solvent were both about three times higher than the contents obtained using SWE $(0.66 \pm 0.04 \mathrm{mg} / \mathrm{g}$ FW and $1.34 \pm 0.07 \mathrm{mg} / \mathrm{g}$ FW, respectively) from chokeberries. This result is consistent with a previous study finding that the anthocyanin extraction efficiency for grape skin increased when using $\mathrm{SO}_{2}$ (sulfur dioxide) as the extraction solvent [12]. Another study found that a lower $\mathrm{pH}$ resulted in less heat-related damage to anthocyanin [23]. It also has been reported that a lower $\mathrm{pH}$ will increase the storage period of anthocyanin [24]. Anthocyanin is a flavylium cation in an acidic condition, which is more stable than in other conditions [6]. Therefore, it was concluded that the extraction efficiency when using $1 \%$ citric acid was higher than when using water. The $\mathrm{pH}$ decreased by about 1.30 for the extraction performed at $190{ }^{\circ} \mathrm{C}$ (the $\mathrm{pH}$ was 3.78 with water and 2.48 with $1 \%$ citric acid). Water at a higher temperature also exhibits a better dissociation reaction, and a solvent has a lower $\mathrm{pH}$ at a higher temperature [25]. During our experiment, we used $1 \%$ citric acid (which is an organic acid) to reduce the $\mathrm{pH}$ of the solvent, which increased the extraction efficiency of the anthocyanin. Citric acid was used for the extraction of the berries since it is edible, and malic acid, tartaric acid, acetic acid, and ascorbic acid also could be used as extraction solvents. Regarding the $\mathrm{pH}$ range, using $\mathrm{pH}$ values from 1 to 4 will result in the anthocyanin remaining stable, but the $\mathrm{pH}$ should be at least 2 for the extract to be edible [24].

\subsection{Effect of Flavonoids Content and Antioxidant Activity}

Figure 4 shows the total flavonoid contents and antioxidant activity of blueberry and chokeberry extracts and, in the subcritical-water extraction (SWE) condition, both increased continuously with temperature and time. The extraction temperature had a positive effect on the extraction of phenolic compounds such as flavonoids [26,27]. Regarding the case of the total flavonoid content of the chokeberry extract, it decreased at $190{ }^{\circ} \mathrm{C}$ for $5 \mathrm{~min}$ and $10 \mathrm{~min}$.

Additionally, the changes in the ferric-reducing antioxidant power (FRAP) antioxidant activities of the extracts were similar to those of the total flavonoid contents. While the total flavonoid contents and antioxidant activity showed similar tendencies, the total anthocyanin content did not. The content of anthocyanin tended to decrease with an increasing extraction temperature and time. Ju et al. [12] found similar results for anthocyanin extracted from grape skin using SWE, with the anthocyanin content decreasing but the antioxidant activity increasing as the extraction temperature increased.

There are two possible reasons for these results. The first is the effect of substances other than anthocyanin. Flavonoids include not only anthocyanin but also flavanol species such as catechin and proanthocyanin, as well as quercetin. Blueberries and chokeberries contain many other compounds besides anthocyanin. They have a higher content of polymeric procyanidin, and they contain many antioxidant flavonoids, such as chlorogenic acid, (-)-epicatechin, and quercetin [28]. The second possible reason is the effects of the degradation compounds of anthocyanin [29,30]. Anthocyanin undergoes degradation at high temperatures via weakening of the structure of its skeleton ring. The separated materials mainly include coumaric acid, gallic acid, and benzoic acid. Since all of these substances have antioxidant abilities, the antioxidant ability could be increased even though the content of anthocyanin is decreased at high temperatures. Therefore, the extraction of 
components other than anthocyanin at high temperatures would affect the tendency for the total flavonoid content and antioxidant activity to increase.
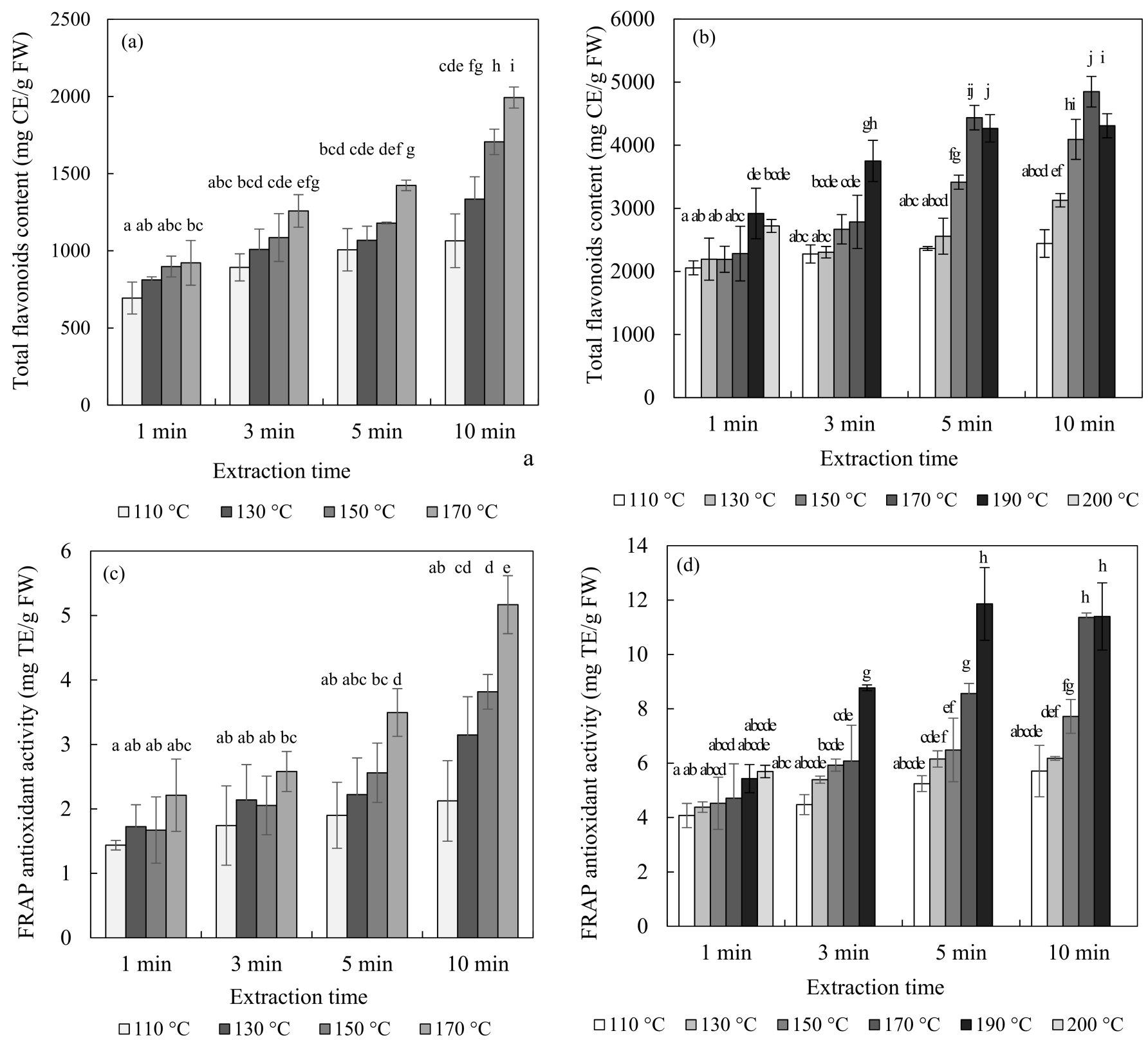

Figure 4. Total flavonoid content and ferric-reducing antioxidant power (FRAP) antioxidant activity of blueberry (a,c), and chokeberry (b,d) extracts according to the extraction time and temperature in subcritical-water extraction (SWE) $(n=3)$. TE (trolox equivalent), FW (fresh weight), CE (catechin equivalent). Means in bars with same letters are not significantly different according to Duncan's test at $p<0.05$.

\section{Conclusions}

To conclude, this study determined the optimal extraction conditions for the subcriticalwater extraction (SWE) of anthocyanin from blueberries and chokeberries and compared the performance using conventional extraction methods. The anthocyanin yields using SWE were higher than when using hot-water extraction or a pressed-juice extract. SWE is a faster and more-efficient method for extracting anthocyanin from blueberries and chokeberries than conventional extraction methods. This study demonstrates the feasibility of applying SWE to the food processing industry. This method can be easily implemented on an industrial scale. 
Supplementary Materials: The following are available online at https:/ /www.mdpi.com/2304-815 8/10/3/527/s1, Figure S1: HPLC chromatograms of the extracts obtained from blueberries; Malvidin3-galactoside (A), and chokeberries; cyanidin-3-galactoside (B), Figure S2: Spectral characteristics of the extracts in buffers at $\mathrm{pH} 1$ (solid line) and $\mathrm{pH} 4.5$ (dashed line). Figure S3: Relationship between the $\mathrm{pH}$ differential method and the HPLC method for the blueberry (A), and chokeberry (B) extracts.

Author Contributions: Conceptualization, M.-S.C. and M.-J.K.; formal analysis, M.-J.K. and H.-J.K.; investigation, H.-J.K.; data curation, M.-J.K. and H.-J.K.; writing-original draft preparation, M.-J.K. and H.-J.K.; writing-review and editing, M.-S.C., M.-J.K. and H.-J.K.; supervision, M.-S.C.; project administration, M.-S.C. All authors have read and agreed to the published version of the manuscript.

Funding: This work was supported by the National Research Foundation of Korea (NRF) grant funded by the Korea government (MSIT) (No. 2019R1G1A1002220) and Ottogi Corporation.

Institutional Review Board Statement: Not applicable.

Informed Consent Statement: Not applicable.

Data Availability Statement: Supplementary data associated with this article can be found.

Conflicts of Interest: The authors declare no conflict of interest.

\section{References}

1. Denev, P.; Ciz, M.; Kratchanova, M.; Blazheva, D. Black chokeberry (Aronia melanocarpa) polyphenols reveal different antioxidant, antimicrobial and neutrophilmodulating activities. Food Chem. 2019, 284, 108-117. [CrossRef]

2. Heinonen, I.M.; Meyer, A.S.; Frankel, E.N. Antioxidant activity of berry phenolics on human low-density lipoprotein and liposome ion. J. Agric. Food Chem. 1998, 46, 4107-4112. [CrossRef]

3. Jennings, A.; Welch, A.A.; Fairweather-Tait, S.J.; Kay, C.; Minihane, A.M.; Chowienczyk, P.; Jiang, B.; Cecelja, M.; Spector, T.; Macgregor, A.; et al. Higher anthocyanin intake is associated with lower arterial stiffness and central blood pressure in women. Am. J. Clin. Nutr. 2012, 96, 781-788. [CrossRef]

4. Wang, S.Y.; Lin, H. Antioxidant activity in fruits and leaves of blackberry, raspberry, and strawberry is affected by cultivar and maturity. J. Agric. Food Chem. 2000, 48, 140-146. [CrossRef] [PubMed]

5. Ananga, A.; Georgiev, V.; Ochieng, J.; Phills, B.; Tsolova, V. Production of anthocyanins in grape cell cultures: A potential source of raw material for pharmaceutical, food, and cosmetic industries. In The Mediterranean Genetic Code-Grapevine and Olive; Intechopen: London, UK, 2013; Chapter 11; pp. 247-287.

6. Laleh, G.H.; Frydoonfar, H.; Heidary, R.; Jameei, R.; Zare, S. The effect of light, temperature, pH and species on stability of anthocyanin pigments in four Berberis species. Pakistan J. Nutr. 2006, 5, 90-92.

7. Aliaño-González, M.J.; Jarillo, J.A.; Carrera, C.; Ferreiro-González, M.; Álvarez, J.Á.; Palma, M.; Ayuso, J.; Barbero, G.F.; EspadaBellido, E. Optimization of a novel method based on ultrasound-assisted extraction for the quantification of anthocyanins and total phenolic compounds in blueberry samples (Vaccinium corymbosum L.). Foods 2020, 9, 1763.

8. Patras, A.; Brunton, N.P.; O'Donnell, C.; Tiwari, B.K. Effect of thermal processing on anthocyanin stability in foods; mechanisms and kinetics of degradation. Trends Food Sci. Technol. 2010, 21, 3-11. [CrossRef]

9. Lopes, T.J.; Yaginuma, S.R.; Quadri, M.G.N.; Quadri, M.B. Evaluation of red cabbage anthocyanins after partial purification on clay. Braz. Arch. Biol. Technol. 2011, 54, 1349-1356. [CrossRef]

10. Ibañez, E.; Kubátová, A.; Señoráns, F.J.; Cavero, S.; Reglero, G.; Hawthorne, S.B. Subcritical water extraction of antioxidant compounds from rosemary plants. J. Agric. Food Chem. 2003, 51, 375-382. [CrossRef]

11. Ko, M.J.; Cheigh, C.I.; Cho, S.W.; Chung, M.S. Subcritical water extraction of flavonol quercetin from onion skin. J. Food Eng. 2011, 102, 327-333. [CrossRef]

12. Ju, Z.; Howard, L.R. Subcritical water and sulfured water extraction of anthocyanins and other phenolics from dried red grape skin. J. Food Sci. 2005, 70, 270-276. [CrossRef]

13. Monrad, J.K.; Howard, L.R.; King, J.W.; Srinivas, K.; Mauromoustakos, A. Subcritical solvent extraction of anthocyanins from dried red grape pomace. J. Agric. Food Chem. 2010, 58, 2862-2868. [CrossRef]

14. Poiana, M.A.; Moigradean, D.; Raba, D.; Alda, L.M.; Popa, M. The effect of long-term frozen storage on the nutraceutical compounds, antioxidant properties and color indices of different kinds of berries. J. Food Agric. Environ. 2010, 8, 54-58.

15. Weber, F.; Larsen, L.R. Influence of fruit juice processing on anthocyanin stability. Food Res. Int. 2017, 100, 354-365. [CrossRef] [PubMed]

16. Tonon, R.V.; Brabet, C.; Hubinger, M.D. Anthocyanin stability and antioxidant activity of spray-dried açai (Euterpe oleracea Mart.) juice produced with different carrier agents. Food Res. Int. 2010, 43, 907-914. [CrossRef]

17. Lee, J.; Rennaker, C.; Wrolstad, R.E. Correlation of two anthocyanin quantification methods: HPLC and spectrophotometric methods. Food Chem. 2008, 110, 782-786. [CrossRef]

18. Kalt, W.; McDonald, J.E.; Ricker, R.D.; Lu, X. Anthocyanin content and profile within and among blueberry species. Can. J. Plant Sci. 1999, 79, 617-623. [CrossRef] 
19. Chandra, A.; Rana, J.; Li, Y. Separation, identification, quantification, and method validation of anthocyanins in botanical supplement raw materials by HPLC and HPLC-MS. J. Agric. Food Chem. 2001, 49, 3515-3521. [CrossRef] [PubMed]

20. Cheigh, C.I.; Yoo, S.Y.; Ko, M.J.; Chang, P.S.; Chung, M.S. Extraction characteristics of subcritical water depending on the number of hydroxyl group in flavonols. Food Chem. 2015, 168, 21-26. [CrossRef]

21. Ko, M.J.; Cheigh, C.I.; Chung, M.S. Relationship analysis between flavonoids structure and subcritical water extraction (SWE) Food Chem. 2014, 143, 147-155. [CrossRef]

22. Wang, L.; Weller, C.L. Recent advances in extraction of nutraceuticals from plants. Trends Food Sci. Technol. 2006, 17, 300-312. [CrossRef]

23. Kırca, A.; Özkan, M.; Cemeroğlu, B. Effects of temperature, solid content and $\mathrm{pH}$ on the stability of black carrot anthocyanins. Food Chem. 2007, 101, 212-218. [CrossRef]

24. Fossen, T.; Cabrita, L.; Andersen, O.M. Colour and stability of pure anthocyanins influenced by pH including the alkaline region. Food Chem. 1998, 63, 435-440. [CrossRef]

25. Plaza, M.; Turner, C. Pressurized hot water extraction of bioactives. TrAC Trends Anal. Chem. 2015, 71, 39-54. [CrossRef]

26. D'Alessandro, L.G.; Kriaa, K.; Nikov, I.; Dimitrov, K. Ultrasound assisted extraction of polyphenols from black chokeberry. Sep. Purif. Technol. 2012, 93, 42-47. [CrossRef]

27. Harbourne, N.; Jacquier, J.C.; O'Riordan, D. Optimisation of the aqueous extraction conditions of phenols from meadowsweet (Filipendula ulmaria L.) for incorporation into beverages. Food Chem. 2009, 116, 722-727. [CrossRef]

28. Oszmianski, J.; Wojdylo, A. Aronia melanocarpa phenolics and their antioxidant activity. Eur. Food Res. Technol. 2005, 221, 809-813. [CrossRef]

29. Sun, Y.; Zhang, Y.; Xu, W.; Zheng, X. Analysis of the anthocyanin degradation in blue honeysuckle berry under microwave assisted foam-mat drying. Foods 2020, 9, 397. [CrossRef]

30. Alvarez-Suarez, J.M.; Cuadrado, C.; Redondo, I.B.; Giampieri, F.; González-Paramás, A.M.; Santos-Buelga, C. Novel approaches in anthocyanin research-Plant fortification and bioavailability issues. Trends Food Sci. Technol. 2021, 29. [CrossRef] 